\title{
Less Invasive Surfactant Administration in Very Prematurely Born Infants
}

\author{
Sandeep Shetty, MD ${ }^{1,2(0)}$ Helen Egan, MRCPCH ${ }^{1}$ Peter Cornuaud, BSc ${ }^{1}$ Anay Kulkarni, FRCPCH ${ }^{1,20}$ \\ Donovan Duffy, MRCPCH ${ }^{1,2}$ Anne Greenough, $\mathrm{MD}^{3,4,5}$
}

\footnotetext{
${ }^{1}$ Neonatal Intensive Care Centre, St George's University Hospitals NHS Foundation Trust, London, United Kingdom

2 Department of Neonatal Medicine, St George's University of London, London, United Kingdom

${ }^{3}$ Women and Children's Health, School of Life Course Sciences, Faculty of Life Sciences and Medicine, King's College London, United Kingdom

${ }^{4}$ The Asthma UK Centre in Allergic Mechanisms of Asthma, Kings College London, London, United Kingdom

${ }^{5}$ NIHR Biomedical Research Centre at Guy's and St Thomas' NHS Foundation Trust and King's College London, United Kingdom
}

\begin{abstract}
Address for correspondence Sandeep Shetty, MD, Neonatal Unit, St George's University Hospitals NHS Foundation Trust, Tooting, London, SW17 0QT, United Kingdom

(e-mail: sandeep.shetty@stgeorges.nhs.uk).
\end{abstract}

AJP Rep 2021;11:e119-e122.

\begin{abstract}
Keywords

- less invasive surfactant administration

- LISA

- surfactant administration

- BPD

- duration of mechanical ventilation

- length of hospital stay

Background Less invasive surfactant administration (LISA) is the preferred mode of surfactant administration for spontaneously breathing preterm babies supported by noninvasive ventilation (NIV).

Objective The aim of this study was to determine whether LISA on the neonatal unit or in the delivery suite was associated with reduced rates of bronchopulmonary dysplasia (BPD) or the need for intubation, or lower durations of invasive ventilation and length of hospital stay (LOS).

Methods A historical comparison was undertaken. Each "LISA" infant was matched with two infants (controls) who did not receive LISA.

Results The 25 LISA infants had similar gestational ages and birth weights to the 50 controls (28 [25.6-31.7] weeks vs. 28.5 [25.4-31.9] weeks, $p=0.732 ; 1,120$ (580$1,810) \mathrm{g}$ vs. $1,070[540-1,869] \mathrm{g}, p=0.928)$, respectively. LISA infants had lower requirement for intubation ( 52 vs. $90 \%, p<0.001$ ), shorter duration of invasive ventilation (median 1 [0-35] days vs. 6 [0-62] days $p=0.001$ ) and a lower incidence of BPD ( 36 vs. $64 \%, p=0.022$ ). There were no significant differences in duration of NIV (median 26 [3-225] vs. 23 [2-85] days, $p=0.831$ ) or the total LOS (median 76 [24$259]$ vs. $85[27-221], p=0.238)$.

Conclusion LISA on the neonatal unit or the delivery suite was associated with a lower BPD incidence, need for intubation, and duration of invasive ventilation.
\end{abstract}

Prematurely born infants commonly develop respiratory distress syndrome (RDS) requiring some form of respiratory support and potentially surfactant administration. ${ }^{1}$ Surfactant administration improves outcomes. The standard approaches to administer surfactant involve intubation and a period of invasive mechanical ventilation (MV) or the Intubation Surfactant received

December 27, 2020 accepted after revision March 4, 2021
DOI https://doi.org/ 10.1055/s-0041-1735632. ISSN 2157-6998.

\footnotetext{
(C) 2021. The Author(s).

This is an open access article published by Thieme under the terms of the Creative Commons Attribution-NonDerivative-NonCommercial-License, permitting copying and reproduction so long as the original work is given appropriate credit. Contents may not be used for commercial purposes, or adapted, remixed, transformed or built upon. (https://creativecommons.org/ licenses/by-nc-nd/4.0/) Thieme Medical Publishers, Inc., 333 Seventh Avenue, 18th Floor, New York, NY 10001, USA
} 
Extubate (InSurE) technique. ${ }^{2}$ MV can cause damage to the fragile preterm lungs leading to bronchopulmonary dysplasia (BPD), so nowadays practitioners try to avoid intubation. Indeed, the European Consensus Guidelines (20119) on the management of RDS state that less invasive surfactant administration (LISA) is the preferred mode of surfactant administration for spontaneously breathing preterm babies supported by continuous positive airway pressure (CPAP). ${ }^{3}$ During LISA, surfactant is delivered directly into the lungs via a fine bore catheter inserted into the trachea. ${ }^{2}$

The results of six randomized controlled trials (RCTs) comparing LISA to InSurE or MV demonstrated that LISA was associated with a reduction in MV. ${ }^{4-9}$ In systematic reviews, LISA was associated with reduction in duration of MV within 72 hours of birth and BPD (defined as an oxygen requirement at 36 weeks) $)^{10,11}$ and a reduction in the composite outcome of death or BPD at 36 weeks compared with InSurE. ${ }^{2}$ No single study, however, reported a reduction in BPD.

A recent survey demonstrated that LISA is infrequently used in UK neonatal units and very rarely performed in the delivery suite. ${ }^{12}$ We have been using LISA both on the neonatal unit and in the delivery suite. Our aim was to determine in our center whether LISA was associated with reduced rates of BPD or the need for intubation or lower durations of invasive MV and hospital stay by comparing the outcomes of infants who had LISA to matched historical controls.

\section{Materials and Methods}

Each infant who received LISA was matched retrospectively with two other infants (controls) who required respiratory support. The infants were compared with a historical cohort born between June 2015 and July 2018. The infants were matched by gestational age, birth weight, sex, antenatal steroid exposure, and whether they were inborn or transferred ex utero. Infants were identified from a standardized electronic neonatal database (BadgerNet, UK Neonatal Patient Data Management). The study period was between July 2018 and March 2020. This project was registered with St George's University Hospitals NHS Foundation Trust (SGH) audit department.

LISA was delivered via a LISAcath, a thin straight catheter that was passed through the vocal cords and into the trachea. Infants were administered LISA in the delivery suite if they were more than or equal to 25 weeks of gestation at birth and stable on CPAP in the delivery suite with a fraction of inspired oxygen $\left(\mathrm{FiO}_{2}\right)$ requirement of more than 0.3 or had an increased work of breathing. On the neonatal unit, infants had LISA if they were more than or equal to 25 weeks of gestation at birth and were less than 72 hours of postnatal age with an $\mathrm{FiO}_{2}$ requirement of more than 0.3 , or had an increased work of breathing (excluding pneumothorax) or worsening blood gases with a respiratory acidosis $(\mathrm{pH}<7.2$, partial pressure of carbon dioxide $\left[\mathrm{PCO}_{2}\right]>8.7 \mathrm{kPa}$ ). The dosage of surfactant was aimed to be between 100 and $200 \mathrm{mg} / \mathrm{kg}$ and rounded closest to 120 or $240 \mathrm{mg}$ to minimize vial use. The historical controls were given surfactant and ventilated if they had $\mathrm{FiO}_{2}$ requirement more than 0.3 , or had an increased work of breathing (excluding pneumothorax) or worsening blood gases with a respiratory acidosis $(\mathrm{pH}<7.2$, $\mathrm{PCO}_{2}>8.7 \mathrm{kPa}$ ). No sedation was given if LISA was performed on the delivery suite. Nonpharmacological methods for analgesia such as swaddling, sucking on a dummy, or sucrose were used when LISA was performed on the neonatal unit. If the baby remained unsettled, then fentanyl was administered $(0.5-1 \mu \mathrm{g} / \mathrm{kg} /$ dose $)$.

The outcomes were the need for intubation within 72 hours of birth, the durations of invasive and noninvasive ventilation, the length of hospital stay (LOS) at SGH and the referring hospital (local hospital), the total LOS, and the incidence of BPD (oxygen requirement at 36 weeks corrected age). In addition, any side effects such as desaturations less than $80 \%$, bradycardia less than 100 beats per minute, apnea, and surfactant reflux were noted. Data were obtained from the electronic documentation recording system and cross checked with the medical notes.

\section{Sample Size}

BPD incidence historically has been around 50\% in infants born less than 32 weeks of gestation in our center at St George's [14]. A sample size of 25 infants in the LISA group and 50 controls allowed detection of a $50 \%$ reduction in BPD in the LISA group controlled to the controls with $85 \%$ power and a significance level of 0.05 .

\section{Analysis}

Differences between the two groups were assessed for statistical significance using the chi-squared test or the Mann-Whitney U test as appropriate using IBM SPPS statistical software, V.25 (IBM Corporation).

\section{Results}

The results of 25 LISA infants were compared with those of 50 controls ( - Table 1 ). Ninety-six percent of the LISA infants and $98 \%$ of the controls had at least one course (two doses) of antenatal corticosteroids $(p=0.612)$. All LISA procedures were performed by the medical team using video laryngoscope; $40 \%$ of the procedures were performed by the neonatal consultant team and $60 \%$ by the members of the junior doctor team. All the infants received caffeine and were inborn and $36 \%$ of infants received LISA in delivery suite. All infants in the LISA group received surfactant and $78 \%$ of the control group received surfactant $(p=0.015$; - Table 1$)$. Forty percent of infants received sedation for LISA. Side effects noted were apnea, desaturations, and bradycardia in $24 \%$ of infants and surfactant reflux was noted in $16 \%$ of infants. Infants who received LISA had significantly lower rates of BPD and need for intubation and shorter durations of invasive ventilation (-Table $\mathbf{2}$ ).

\section{Discussion}

We have demonstrated that prematurely born infants who received LISA had a lower incidence of BPD compared with historical controls. The incidence of BPD in the LISA infants of approximately $30 \%$ is similar to the reported meta- 
Table 1 Demographic data

\begin{tabular}{|l|l|l|l|}
\hline & $\begin{array}{l}\text { LISA } \\
(\boldsymbol{n}=\mathbf{2 5})\end{array}$ & $\begin{array}{l}\text { Control } \\
(\boldsymbol{n}=\mathbf{5 0})\end{array}$ & $p$-Value \\
\hline BW (g) & $\begin{array}{l}1120 \\
(580-1810)\end{array}$ & $\begin{array}{l}1070 \\
(540-1869)\end{array}$ & 0.928 \\
\hline GA (wk) & $\begin{array}{l}28 \\
(25.6-31.7)\end{array}$ & $\begin{array}{l}28.5 \\
(25.4-31.9)\end{array}$ & 0.732 \\
\hline Gender (male) & $19(76 \%)$ & $38(76 \%)$ & 1 \\
\hline $\begin{array}{l}\text { Antenatal } \\
\text { corticosteroids }\end{array}$ & $24(96 \%)$ & $49(98 \%)$ & 0.612 \\
\hline Surfactant & $25(100 \%)$ & $39(78 \%)$ & 0.015 \\
\hline
\end{tabular}

Abbreviations: BW, birth weight; GA, gestational age; LISA, less invasive surfactant administration.

Data displayed as median (range) or \%.

analyses $2,10,11,13$ and the BPD incidence in the control group is similar to previous data from our center. ${ }^{14} \mathrm{~A}$ reduction in BPD has not been demonstrated in individual LISA trials, but in contrast to the other studies $36 \%$ of the infants in our study were given LISA at delivery. The reduction in BPD is likely to be due to a combination of reasons that include a decreased MV duration, reduced intubation rates, and earlier administration of surfactant as $36 \%$ of infants received surfactant in delivery suite.

In previous studies, surfactant reflux, acute desaturations, bradycardia, and/or need for manual ventilation during LISA were observed in less than $10 \%{ }^{4}$ to more than $30 \%{ }^{10}$ of LISA/MIST (minimally invasive surfactant therapy) procedures. Side effects noted in our study were similar to published studies. The dosage of surfactant was aimed to be between 100 and $200 \mathrm{mg} / \mathrm{kg}$ and rounded closest to 120 or $240 \mathrm{mg}$ to minimize vial use. The avoidance of mechanical ventilation trial ${ }^{4}$ used a dose of $100 \mathrm{mg} / \mathrm{kg}$, while the nonintubated surfactant application trial ${ }^{9}$ used a "whole" vial of $120 \mathrm{mg}$ porcine surfactant per infant. In daily routine, a whole vial policy often resulting in doses of $\geq 150 \mathrm{mg} / \mathrm{kg}$ has been widely adopted. ${ }^{12}$ In addition, when LISA is done in the delivery suite, the birth weight has often to be estimated, which makes a "whole" vial approach pragmatic.

In a recent survey, ${ }^{12}$ LISA was performed by consultants in $91.7 \%$ of units, registrars or equivalent in $69.4 \%$, and senior house officer or equivalent in $25 \%$. Only $40 \%$ of LISA procedures were performed by the consultant neonatologists in our center; this may be because video laryngoscopy is routinely used for all intubations resulting in improved confidence in the junior doctors. ${ }^{15}$

Forty percent of infants in our study received sedation for LISA. Most centers undertake LISA without analgesia. ${ }^{12}$ Nonpharmacological methods of analgesia such as positioning, holding ("facilitated tucking"), and/or sucrose solutions are used. A variety of drugs have been studied to provide analgesia/sedation during InSurE or LISA; fentanyl, ketamine, and propofol were the most frequently used medications. The results of studies indicate that those drugs may help to reduce pain scores but may interfere with spontaneous breathing. ${ }^{16}$ Chest rigidity has also been reported when fentanyl is used.
Table 2 Outcomes by LISA status

\begin{tabular}{|l|l|l|l|}
\hline & $\begin{array}{l}\text { LISA } \\
(\boldsymbol{n}=\mathbf{2 5})\end{array}$ & $\begin{array}{l}\text { Control } \\
(\boldsymbol{n}=\mathbf{5 0})\end{array}$ & $p$-Value \\
\hline $\begin{array}{l}\text { Need for intubation } \\
(n)\end{array}$ & $13(52 \%)$ & $45(90 \%)$ & $<0.001$ \\
\hline $\begin{array}{l}\text { Duration of invasive } \\
\text { ventilation (d) }\end{array}$ & $1(0-35)$ & $6 /(0-62)$ & 0.001 \\
\hline $\begin{array}{l}\text { Duration of NIV at } \\
\text { SGH (d) }\end{array}$ & $15(3-225)$ & $\begin{array}{l}15 \\
(2-85)\end{array}$ & 0.766 \\
\hline $\begin{array}{l}\text { Total invasive and } \\
\text { NIV at SGH (d) }\end{array}$ & $21(3-260)$ & $\begin{array}{l}23 \\
(2-147)\end{array}$ & 0.458 \\
\hline $\begin{array}{l}\text { Overall duration of } \\
\text { NIV (d) }\end{array}$ & $26(3-225)$ & $\begin{array}{l}23 \\
(2-85)\end{array}$ & 0.831 \\
\hline LOS at SGH (d) & $34(7-259)$ & $\begin{array}{l}62 \\
(7-221)\end{array}$ & 0.085 \\
\hline Overall LOS (d) & $76(24-259)$ & $\begin{array}{l}85 \\
(27-221)\end{array}$ & 0.238 \\
\hline BPD & $9(36 \%)$ & $32(64 \%)$ & 0.022 \\
\hline
\end{tabular}

Abbreviations: BPD, bronchopulmonary dysplasia; LISA, less invasive surfactant administration; LOS, length of hospital stay; NIV, noninvasive ventilation; SGH, St George's University Hospitals NHS Foundation Trust. Data displayed as median (range) or \%.

Stress and pain in the neonatal period may have long-term negative effects and should be avoided whenever possible, but drugs used for stress/pain relief also have acute and long-term side effects. Likely as a consequence, the practice of using these drugs during LISA varies widely. No RCTs have looked at the use of premedication for LISA.

There are strengths and some limitations to our study. This is the first single-center study that has demonstrated a lower incidence of BPD in infants receiving LISA. Comparison was made to historical controls, but they were matched for gestational age, birth weight, sex, antenatal corticosteroid exposure, and whether inborn or transferred ex utero. The LISA group all received surfactant but only $78 \%$ of the controls received surfactant; we do, however, not feel this influenced our results as surfactant administration per se has not been shown to reduce the development of BPD.

In conclusion, we have demonstrated that LISA given in a single center either in the delivery suite or the neonatal unit was associated with a reduction in BPD.

Availability of Data and Materials

All data from this study are given in tables and as text in manuscript.

\section{Authors' Contributions}

Shetty and Greenough designed the study and approved the final manuscript as submitted. Shetty, Duffy, and Egan collected the data and approved the final manuscript as submitted. Cornuaud and Kulkarni designed the statistical analysis and analyzed the data and approved the final manuscript as submitted. All authors were involved in the preparation of the manuscript and approved the final manuscript as submitted. 


\section{Conflict of Interest}

Greenough holds a grant from Chiesi to examine the physiological effects of LISA in the delivery suite.

\section{Acknowledgments}

We thank our data manager, Peter Cornuaud for data assistance. We are grateful to the consultants and nursing staff at St Georges Hospital for support when introducing LISA and with the study.

\section{References}

1 Bhayat S, Shetty S. Less-invasive surfactant administration (LISA). Paediatr Child Health 2020;30:144-148

2 Aldana-Aguirre JC, Pinto M, Featherstone RM, Kumar M. Less invasive surfactant administration versus intubation for surfactant delivery in preterm infants with respiratory distress syndrome: a systematic review and meta-analysis. Arch Dis Child Fetal Neonatal Ed 2017;102(01):F17-F23

3 Sweet DG, Carnielli V, Greisen G, et al. European Consensus Guidelines on the Management of Respiratory Distress Syndrome - 2019 update. Neonatology 2019;115(04):432-450

4 Göpel W, Kribs A, Ziegler A, et al; German Neonatal Network. Avoidance of mechanical ventilation by surfactant treatment of spontaneously breathing preterm infants (AMV): an open-label, randomised, controlled trial. Lancet 2011;378(9803):1627-1634

5 Kanmaz HG, Erdeve O, Canpolat FE, Mutlu B, Dilmen U. Surfactant administration via thin catheter during spontaneous breathing: randomized controlled trial. Pediatrics 2013;131(02):e502-e509

6 Mirnia K, Heidarzadeh M, Hosseini M, Sadeghnia A, Balila M, Ghojazadeh M. Comparison outcome of surfactant administration via tracheal catheterization during spontaneous breathing with InSurE. Med J Islamic World Acad Sci 2013;21:143-148
7 Bao Y, Zhang G, Wu M, Ma L, Zhu J. A pilot study of less invasive surfactant administration in very preterm infants in a Chinese tertiary center. BMC Pediatr 2015;15:21

8 Mohammadizadeh M, Ardestani AG, Sadeghnia AR. Early administration of surfactant via a thin intratracheal catheter in preterm infants with respiratory distress syndrome: feasibility and outcome. J Res Pharm Pract 2015;4(01):31-36

9 Kribs A, Roll C, Göpel W, et al; NINSAPP Trial Investigators. Nonintubated surfactant application vs conventional therapy in extremely preterm infants: a randomized clinical trial. JAMA Pediatr 2015;169(08):723-730

10 Dargaville PA, Aiyappan A, Cornelius A, Williams C, De Paoli AG. Preliminary evaluation of a new technique of minimally invasive surfactant therapy. Arch Dis Child Fetal Neonatal Ed 2011;96(04): F243-F248

11 Isayam T, Chai-Adisaksopha C, McDonald SD. Noninvasive ventilation with vs without early surfactant to prevent chronic lung disease in preterm infants: a systematic review and meta-analysis. JAMA Pediatr 2015;169:73

12 Jeffreys E, Hunt K, Dassios T, Greenough A. UK survey of less invasive surfactant administration. Arch Dis Child Fetal Neonatal Ed 2019;104(05):F567

13 Rigo V, Lefebvre C, Broux I. Surfactant instillation in spontaneously breathing preterm infants: a systematic review and metaanalysis. Eur J Pediatr 2016;175(12):1933-1942

14 Shetty S, Milne E, Cornuaud P. Trends in BPD data over 9 years in a single tertiary surgical neonatal centre. Eur J Pediatr 2019; 178:1747

15 Zhou M, Xi X, Li M, Wang S, Liu Z, Liu JQ. Video laryngoscopy improves the success of neonatal tracheal intubation for novices but not for experienced medical staff. Front Pediatr 2020;8:445

16 Dekker J, Lopriore E, van Zanten HA, Tan RNGB, Hooper SB, Te Pas $A B$. Sedation during minimal invasive surfactant therapy: a randomised controlled trial. Arch Dis Child Fetal Neonatal Ed 2019;104(04):F378-F383 